\title{
Analysis of lard's aroma by an electronic nose for rapid Halal authentication.
}

\begin{abstract}
An electronic nose was successfully used to detect and discriminate lard from other types of animal body fats and samples containing lard. The results are presented in the form of VaporPrint ${ }^{\mathrm{TM}}$, the image of the polar plot of the odor amplitudes from the surface acoustic wave (SAW) detector frequency. In the VaporPrint ${ }^{\mathrm{TM}}$, the radial angles representing the sensor provides individual fingerprints of the aroma of different animal body fats. Principal component analysis (PCA) was used to interpret the data and it provided a good grouping of samples, with $61 \%$ of the variation accounted for by PC 1 and $29 \%$ accounted for by PC 2 . All of the lard-containing samples formed a separate group from the samples that were free from lard. This method can be developed into a rapid method for detecting the presence of lard in food samples for Halal authentication.
\end{abstract}

Keyword: Adulteration; Electronic nose; Halal authentication; Lard; Principal component analysis (PCA). 